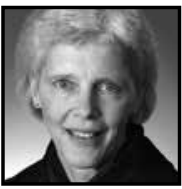

\title{
A Look at Grade 2 Writing: Successes and Challenges in Early Literacy Development
}

\author{
Hetty Roessingh, University of Calgary
}

\begin{abstract}
The keys to early literacy development to the end of Grade 2 are a strong foundation in the skills of printing and spelling. These provide the underpinnings that unlock the cognitive and linguistic resources youngsters are developing in the early stages of literacy learning. Illustrative examples of children's efforts in the writing process at the end of Grade 2 demonstrates the complex interaction between skills, cognitive and metacognitive thought processes, and vocabulary knowledge that launch youngsters into the next steps of literacy-one that significantly challenges them.
\end{abstract}

\section{Introduction}

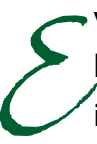

very year of educational advancement in a child's life presents distinct challenges. For youngsters in $\mathrm{K}-3$, perhaps the single most significant achievement is the beginnings of writing: simply put, being able to transform and transpose thought to words to print, and shaping their ideas into coherent text to share with their intended readers - in itself a magical, mysterious process (Wolf, 2007). Grade 2 is an important milestone in this process: a growing body of research identifies this juncture as the point where "language by hand" (i.e., printing) must become legible and controlled and spelling must become increasingly accurate. Both of these skills must become automatized sufficiently by the early months of Grade 3 for youngsters to be able to unlock the cognitive and linguistic resources that have also been developing, so they may engage with the demands of curriculum and increasingly complex and sophisticated modes of writing in upper elementary school. 
Evidence from standard measures across Canada suggests that students at all levels in the educational trajectory fall short in their writing proficiency (Roessingh, 2012a). This inquiry reports on an action research project that describes an analysis of 20 samples of Grade 2 children's writing and which also considers steps for instructional interventions that can support their ongoing quest to control the conventions of printing and spelling, and to increase vocabulary knowledge. Thus, it is that children can improve their abilities to communicate their ideas and thoughts in writing. The questions that frame this inquiry may be stated this way:

1) What is the role of printing and spelling in early literacy development, and how can these be evaluated in holistic terms by classroom practitioners?

2) How do children mobilize their spelling knowledge in the service of attempting to use their unfolding linguistic resources?

3) What are the early indicators of children's use of more sophisticated vocabulary in their written efforts and how are these influenced by the skills of spelling and writing?

An illustrative sample of excellent writing is included to reflect on these questions. This article is intended to give classroom practitioners insights into children's unfolding language and literacy development. In addition, this article seeks to provide practical, pragmatic approaches to looking at children's writing in hopes that this will inform instructional decision-making and informal assessment approaches in the classroom.

\section{Conceptual Framework}

This inquiry recruits its theoretical underpinnings from the research literature in early language and literacy development, most importantly studies relating to printing/transcribing and spelling, and studies relating to the role of vocabulary knowledge in generating precise and nuanced prose, beginning at an early stage of literacy development. These streams of research are briefly surveyed below.

Over the past 30 years there have been opposing views presented in the literature on the role and significance of printing and spelling as they may influence children's written efforts. For many years, time spent on writing, especially cursive form, has been presented in a negative light as an outmoded, even quaint skill-a relic of by-gone times when children submitted their printing for penmanship competitions. In the U.S. it has been dropped as a requirement from the Common Core State Standards (Korbey, 
2013). Keyboarding and voice recognition software are thought to be a replacement for handwriting. More recently, however, there has been a resurgence of interest and recognition in the importance of direct instruction in the underlying skills of printing/writing and spelling (Berninger, 1999; Berninger \& Fayol; 2008; Christensen, 2009; Bounds, 2010; Morin, LaVoie, \& Montesinos, 2012).

Jones and Christensen (1999) underscore the importance of language by hand, as well as its speed and fluency, as a contributor to cognitive processes involved in composition. They highlight the complexity of the writing process, and the competing demands placed on the working memory if the low-level developmental skills are not fully automatized. Working memory has only a small, limited capacity to attend to the immediate demands placed on it. Thus, if a child's handwriting is very slow and belabored, he or she will have difficulty translating thought to words to print, and monitoring his/her work through metacognitive mechanisms for editing and revising, for example. In various studies cited in their work, Jones and Christensen note that both quantity and quality of written production is linked to speed and fluency of the underlying skills. These findings are consistent with work cited above, primarily led by Berninger in a series of studies over the past two decades. Alston (1983) provides a useful framework with illustrative samples of evaluating children's writing in Grade 2. Features to look for include spacing, letter formation, consistency, and fluency.

Similarly, spelling accuracy contributes to fluency in writing. When children are able to accurately and fluently put pencil to paper, their productive efforts are enhanced. Once again, spelling learned through outdated approaches such as memorizing lists of decontextualized words, and looking up and writing out dictionary definitions, may not have been replaced with a contemporary, more meaning-focused approach to learning the spellings of words (Joshi, Treiman, Carreker, \& Moats, 2008). As a consequence, both spelling and writing instruction have largely been marginalized on the curriculum over the past two decades. According to Gentry (1982), children at grade 2 should be in a transitional phase, edging toward correct spelling by the end of Grade 3. Temple, Nathan, and Temple (2013) note that youngsters draw on multiple sources of linguistic and cognitive information as they refine their spelling acumen, however, developmental stages are visible in their written efforts. Memorizing, recognizing patterns, and understanding word structure and meaning (morphology) are all amenable to direct instruction and together support the development of accuracy in spelling skills.

Finally, there is a growing body of research evidence suggesting that vocabulary knowledge plays a far greater role in reading and writing than previously thought (Biemiller, 2003). Youngsters who speak a language other than English at home, a 
growing demographic in Canadian schools both urban and rural, are at heightened educational risk due to their linguistic vulnerability (August, Carlo, Dressler, \& Snow, 2005; Roessingh \& Elgie, 2009). While the early stages of literacy development tend to privilege narrative genre that can largely be accomplished with a limited, familiar vocabulary, the shift that begins to occur at the end of Grade 2 to expository modes of writing such as recounts, descriptions, sequence of events, and problem solving, requires nuanced and precise uses of vocabulary as well as a knowledge of text structure (Moss, 2004). The underlying skills together with vocabulary knowledge and genre understanding converge to challenge children to put their thoughts on paper. In the following section the procedures used to analyze children's writing are described and reported, and an illustrative example of excellent writing is included to demonstrate the successes realized and the challenges that lie ahead.

\section{Analyzing Children's Writing}

Twenty masked samples of Grade 2 children's writing were submitted to me in June 2013 by teachers participating in a school-based action research project. My role over the past year has been to mentor and coach the teachers, and to provide professional development activities including accessible scholarly research articles that would support them in their goal-setting for school improvement planning with a focus on vocabulary development across all grades. The objective of analyzing the writing samples was primarily to note and report baseline information on children's vocabulary use in a spontaneous piece of writing taken during class time as part of the normal instructional activities.

The children were asked to write to a prompt asking them to make a proposal for renovating the local Calgary Zoo. The samples were analyzed for the following:

1) A holistic score using a trait-based rubric for the overall quality of the writing: (4) Excellent, (3) Proficient, (2) Adequate, and (1) Limited.

2) A holistic score for spelling using a rubric adapted from Gentry's (1982) framework: (4) Correct, (3) Transitional, (2) Phonetic, and (1) Semi-pre-phonetic. Note that the pre-communicative stage is not assigned a value, thus reducing Gentry's five stages to four.

3) A spelling error score calculated by counting individual errors by the number of different words generated in the writing sample. 
4) A holistic score for printing based on Alston's (1983) framework.

5) A vocabulary profile using public domain software available at www.lextutor.ca/vp/ kids. This tool generates a profile from a sample of written discourse input into the site. Various indices of lexical diversity are reported including the total number of words (TNW), number of different words (NDW), and a coverage or use of words from high frequency words to low. The goal is to see evidence of children's increased use of more words, and especially a shift to words of mid to low frequency.

Taken as a whole, the samples reflected a number of useful insights. These are briefly described next, followed by a sample of one student's work that exemplifies the standard of excellence for Grade 2 writing.

The first thing noted aside from the writing itself was the pre-writing activity of sketching and coloring. The samples demonstrated a high degree of engagement with the task set to the children, a key requirement for eliciting samples that reflect a child's best efforts (Roessingh, 2012b). In a nutshell, this task was designed to provide challenge, while involving the children in a motivating, authentic activity that set the lexical bar very high. The goal was to elicit the full range of lexical resources available. The coloring and sketching appeared to provide a type of priming activity and a concrete starting point or scaffold for the writing itself. Figure 1 below is a representative sketch of that priming activity.

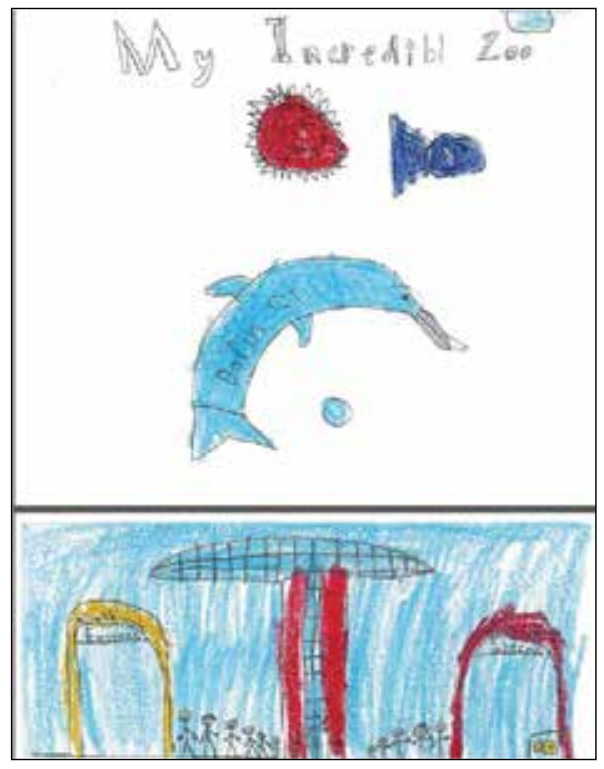

Fig. 1: Sample sketch 
The holistic, qualitative score for the class set of papers reflects a distribution of scores represented in the provincial data as well (Roessingh, 2012a). Some $20 \%$ of the children's writing was scored as either "proficient" or "excellent" with $90 \%$ of the writing reaching the standard that might be expected of Grade 2. The content of the writing ranged from including amusement parks, themed areas (e.g., Jurassic Park), an aquarium, an Arctic display, pandas, Canadian wildlife, African wildlife, and more.

The vast majority of these writing samples reflected spelling in Gentry's (1982) transitional stage: exactly where the extant research suggests they should be at the end of Grade 2. Four of the samples were scored at the "correct" stage. Spelling was a strength for this class group. Very good efforts to systematically apply phonics rules for words not under control are noted. Many of these words are unfamiliar words or words that are not normally used in everyday conversational contexts, but that children might have heard in teacher-led classroom discussions or conversations with adults at home: "jieraf" (giraffe), "pengwens" (penguins), "creayt" (create), "egzibits" (exhibits), "pepal" (people), "difrent" (different), "incredibal" "incredibl” (incredible), "pease” (piece), "macanicul" "michanicle" (mechanical), "opinyin" (opinion), "speises" (species). There were just a few errors with patterned spelling: "peting" (petting) and "galoping" (galloping).

In addition, error rates were calculated for each sample, and again, this was an area of strength for this class group: four of the samples were near perfect ( $95 \%$ accuracy in spelling or more).

A holistic score was given for each sample for printing, taking into consideration features such as spacing, letter shape, and consistency. Alston's (1983) framework and illustrative samples of children's writing at age seven provided the model to accomplish this task. Here again was evidence of success within this group of children: most of the writing was scored as neat, controlled, and highly legible, though the impression of fluency/speed and ease of production was visible in just a few of the papers. Perhaps this is not only a matter of more practice, but also a shift to making letter connections in the development of a type of hybrid form of writing sometime in the next year.

Finally, each sample was transcribed, digitalized and the spelling corrected in preparation for submitting the sample to the vocabulary-profiling tool available at www.lextutor.ca/vp/kids. The data generated from these profiles was input to create a database recording all of the data described above. Due to the limits of the small sample size of just 20 papers, it is beyond the scope of this brief article to offer a more detailed analysis and interpretation of these data: they are part of a larger, ongoing longitudinal project investigating children's unfolding academic literacy skills over time. However, a few brief observations are worth mentioning. 
Most striking was the enormous range in the vocabulary resources available at an individual level. This was visible in both the length (total number of words: TNW) and the number of different words (NDW) within the class. The range in TNW was from 29 to 196 words produced; average of 75 words. NDW from 17 to 111 words; average of 49 different words. In sum, within this class, the better papers were longer, used more and more varied vocabulary, and demonstrated strong spelling and printing skills.

Figure 2 demonstrates a writing sample at the standard of excellence. It is followed by the transcribed sample, the vocabulary profile, and some explanatory comments to guide the reader through the profile report.

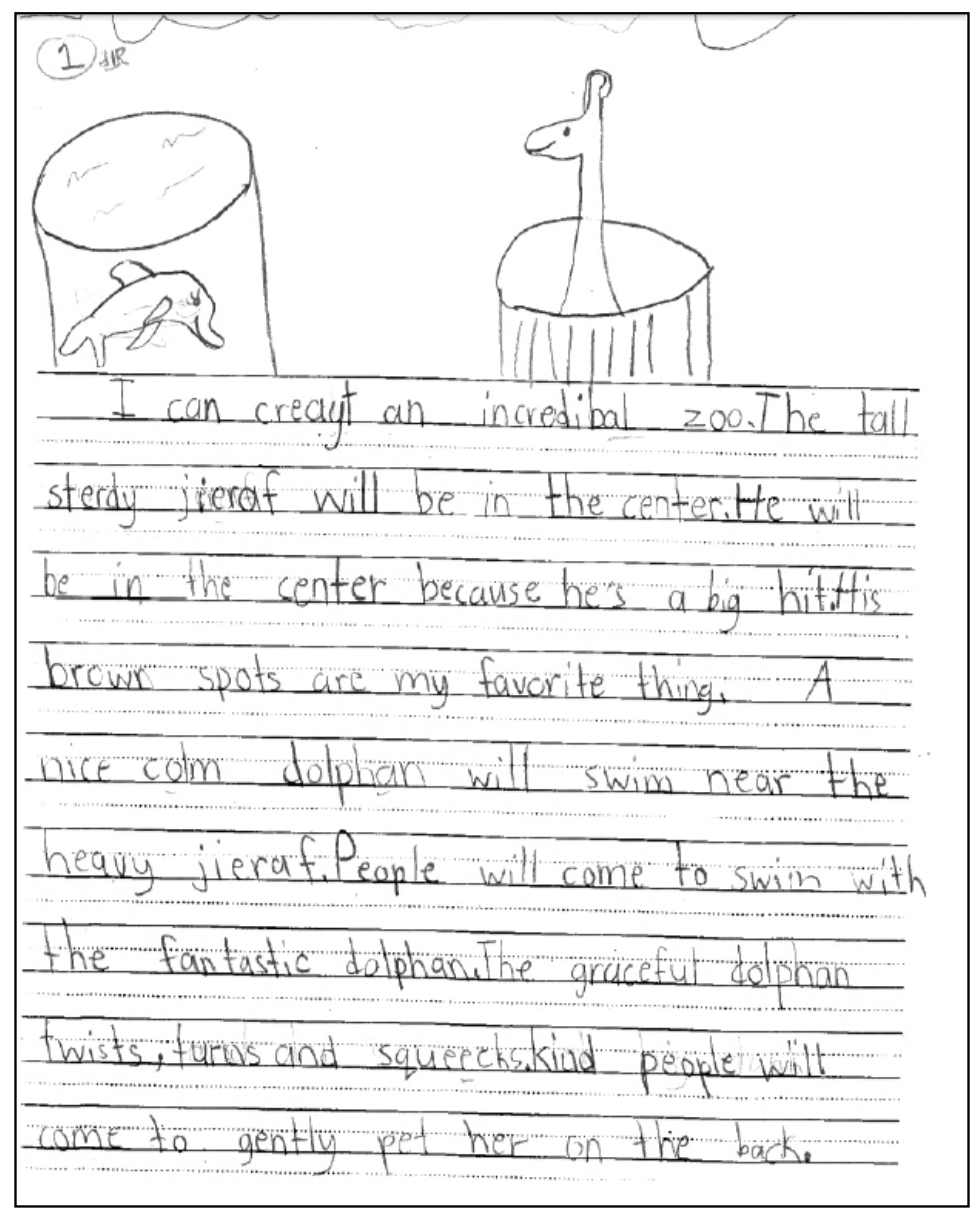

Fig. 2: Handwritten sample of excellent writing 
I can create an incredible zoo. The tall sturdy giraffe will be in the center. He will be in the center because he's a big hit. His brown spots are my favorite thing. A nice calm dolphin will swim near the heavy giraffe. People will come to swim with the fantastic dolphin. The graceful dolphin twists, turns and squeaks. Kind people will come to gently pet her on the back. Ferocious tigers will roam in their humungous glass cage. A mother tiger protects her precious cubs. They play and eat with their mother. When the adorable cubs fall asleep for their nap they look so cute. Birds squawk and squawk. They eat their food and drink water. People take pictures while admiring the colorful wings. They are my favorite part of the zoo! I will also put owls in my zoo. There are going to be lots of different kinds of owls. Like the snowy owl and the great gray owl. All the owls are going to have infants. There is also going to be a zebra. And there are going to be one mom and 3 baby zebras too. And one giant daddy zebra.

Fig. 3: Transcribed sample of excellent writing

\section{A closer analysis of the writing.}

196 words. (Overall: 4, Excellent). Sketching and drawing as pre-writing seemed to engage the youngster. Sixteen spelling mistakes $(16 / 111=86 \%)$, but these are systematic and reflect a great understanding of phonics as well as a "just about grasp" of many sight words. She/he really wanted to "push" and use words not under written control (create/creayt; giraffe/jieraf; dolphin/dolphan; ferocious/furotious; precious/perishes). This kind of risk taking should be encouraged, and reflects confidence that meaning will be conveyed. This youngster shows many early strengths with her writing: it reflects a strong sense of "flow" already with control over the kinesthetic requirements of "pushing the pencil." This allowed for the generation of all of her ideas and creative thoughts. Good sense of task demand. Well developed and elaborated. Great use of descriptors (adorable, precious) and good effort at creating cohesion through anaphoric pronoun references (he/his, they), repetition (dolphin), use of open class nouns (people), examples (snowy and great gray owl). 


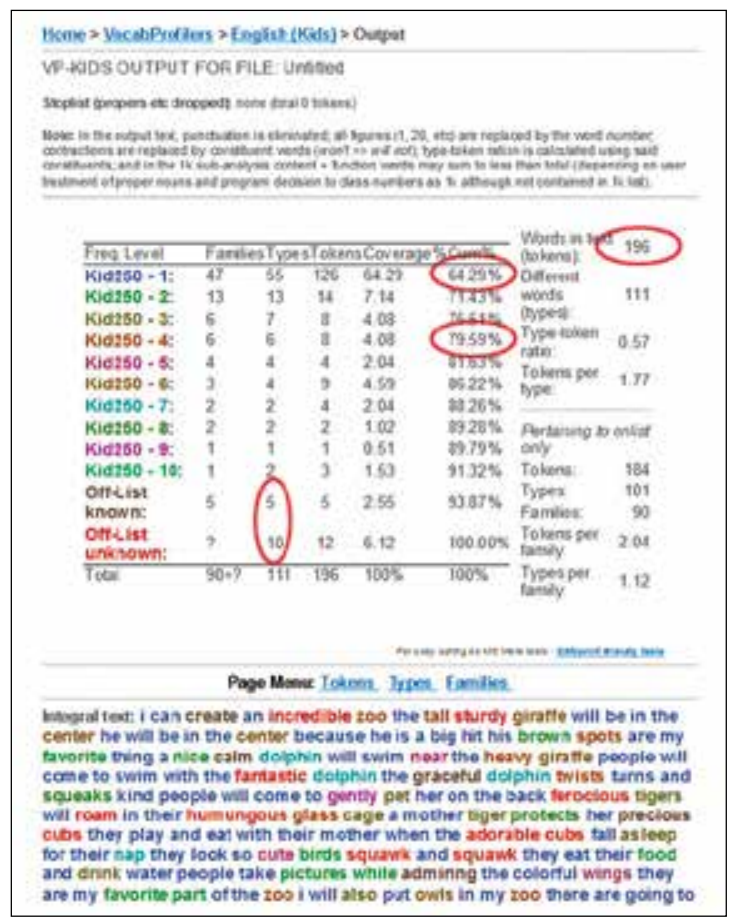

Fig. 4: Vocabulary profile of sample of excellent writing

VP profile is "rainbow-like," reflecting a lexical richness throughout: sturdy, roam, nap, calm, ferocious, precious, adorable. This writer does not over-depend on the high frequency (blue-coded words): doing so would have resulted in an "ocean" effect of predominantly blue-coded words. At Band 1, some $64.20 \%$ of the words have been used. At Band 4, 79.59\% coverage is realized. The control over mid- to low-range vocabulary, words that might be described as Tier 2 words (Beck, McKeown, \& Kucan, 2002), is noteworthy: "adorable" is more nuanced and precise than "cute" and "small"; "roam" versus "walk." This youngster has used 15 words that stretch beyond the oral vocabulary repertoire of childhood-the "off-list known and unknown" words, and is beginning to extend productive vocabulary by way of words that represent more academiclike choices. This reflects a very strong profile (see Roessingh, 2012b). At 196 words in length, the writing is elaborated, developed, and very long for only a Grade 2 student at the end of the year!

This sample of excellent writing suggests this youngster "has it all." Most importantly, this writing suggests that strengths in printing and spelling lessen the cognitive load, unleashing the resources needed to generate ideas and to retrieve the vocabulary available to encode them. 
In summary, to return to the three orienting questions, it would seem that printing and spelling play a key role in early literacy development, and they can be evaluated in holistic terms by classroom practitioners by way of simple frameworks and rubrics that have practical utility. Children mobilize their spelling knowledge in the service of attempting to use their unfolding linguistic resources by applying phonics information. Those with confidence in this skill are often risk takers, and this should be encouraged. Their spelling proficiency will catch up, over time. In the meantime, it is important for children to be supported in formulating their thoughts and putting them on paper for sharing with others over space and time: the magic of literacy learning. Early indicators of children's use of more sophisticated vocabulary in their written efforts are visible in the vocabulary profiles. They "stretch" from high- to low-frequency word use again, applying their spelling knowledge as best they can. Their writing appears well shaped, fluent, and under control.

\section{Challenges for Grade 3: Next Steps}

The writing demands in Grade 3 begin to accelerate in terms of vocabulary use associated with the requirements of the shift to expository modes of writing. Children who do not have the skills of printing and spelling under control may become increasingly frustrated with their inability to put to paper the language they may have. For other youngsters, especially English language learners (ELLs) - those for whom English is not the language of the home-apparent strengths in printing and spelling may quickly forestall further achievement in realizing a successful transition from early literacy to academic literacy development. This is largely dependent on a large and sophisticated vocabulary knowledge that can be marshalled, mobilized, and manipulated for the purposes of achieving academic tasks set by the curriculum and the teacher.

Teachers need to consider collecting an array of evidence that reflects on successful literacy-through-language learning and the associated skills needed. For this particular class cohort, three goals for the future were identified. First and foremost, a direct and explicit focus on vocabulary development is suggested (Biemiller, 2001), especially strategically targeting the mid- to low-range words that start to become central to academic literacy in the upper elementary school years. What native speaking children acquire through immersion, largely at home, ELLs must learn from their teachers. Words beyond the conversational domain (i.e., words that have Latin roots and that will increasingly appear in the informational texts children will encounter) also become central in children's learning needs, especially ELLs. Teacher-led discussions and 
academic conversations on topics such as endangered species (Roessingh \& Douglas, 2013) and teaching word analysis strategies are appropriate at this age.

Second, a shift to teaching expository modes of writing is timely at this point. Writing about procedures (e.g., recipes); instructions (e.g., how to play a given game or sport); recounts, descriptions, and sequence of events, are within reach (Moss, 2004). Part and parcel of this shift is teaching pre-writing and planning activities including drawing, sketching, listing, webbing as well as teaching the attendant skills of revising and editing upon completion of the writing task, perhaps using the peer group as a resource. Supportive and specific feedback are key to improving children's writing here.

Third, children need to shift to a writing style that is connected and allows them to develop fluency/speed while being legible (Morin, LaVoie, \& Montesinos, 2012). This will help lower the cognitive bar and open up scarce, precious working memory space needed to generate thought, retrieve vocabulary (Berninger \& Fayol, 2008), and deploy metacognitive skills for monitoring, revising, and editing their work.

\section{Concluding Comments}

It is overwhelmingly evident that children in Grade 2 are busy youngsters with a lot to learn. A more balanced, process approach to the early literacy curriculum is advocated: one that addresses the basic skills of printing and spelling in ways that engage youngsters in authentic, purposeful work, in contexts that are motivating and interesting for them. There is a role for direct and explicit instruction in the foundational skills as well as for time to be made available for mindful and effortful practice both at school and at home (Wren-Lewis, 2011). New genres associated with written expository modes, together with their structure, can be introduced as children begin to make the shift from literacy through language to language through literacy. There needs to be a strong focus on vocabulary learning for all youngsters. This requires a sustained, longitudinal effort. Finally, opportunities for celebrating and sharing their written efforts will remind youngsters that the outcomes of their written, creative work are nothing short of miraculous. By crossing this threshold in their literacy development, they become empowered to contribute in the give-and-take of a world of print materials in which they, too, can participate. 


\section{Acknowledgments}

I am grateful to be working with Foundations of the Future Charter Academy, Calgary in a collaborative, action research project tracking and intervening in students' literacy development over time. Special thanks to Jay Pritchard, Superintendent; Lorie Skaper-Burtch, Co-ordinator of Instruction; and Brandi Symonds, Grade 2 teacher for their work on this portion of the project. Finally, not only do I recognize the support of a SSHRC Insight Development Grant (2012) that allows for community-engaged research and project work, but also the development of the lexical profiling tools that permits a look at children's vocabulary in use.

\section{References}

Alston, J. (1983). A legibility index: Can handwriting be measured? Educational Review, 35(3), 237-242. Retrieved from http://dx.doi. org/10.1080/0013191830350305

August, D., Carlo, M., Dressler, C., \& Snow, C. (2005). The critical role of vocabulary development for English language learners. Learning Disabilities Research and Practice, 20(1), 50-57.

Beck, I. L., McKeown, M. G., \& Kucan, L. (2002). Bringing words to life: Robust vocabulary instruction. New York: Guilford.

Berninger, V. (1999). The'write stuff'for preventing and treating disabilities. Perspectives International Dyslexia Association. Retrieved from http://www.ldanh.org/docs/writestuff.pdf

Berninger, V., \& Fayol, M. (2008). Why spelling is important and how to teach it effectively. Encyclopedia of Language and Literacy Development (pp. 1-13). London, ON: Canadian Language and Literacy Research Network. Retrieved from http:// www.literacyencyclopedia.ca/pdfs/topic. php?topld=234

Biemiller, A. (2001). Teaching vocabulary: Early, direct and sequential. American Educator, Spring, 2001. http://www.aft.org/newspubs/ periodicals/ae/spring2001/biemiller.cfm
Biemiller, A. (2003). Oral comprehension sets the ceiling on reading comprehension. American Educator, Spring, 2003. http://www.aft.org/ newspubs/periodicals/ae/spring2003/ hirschsboral.cfm

Bounds, G. (2010). How handwriting trains the brain. The Wall Street Journal. October 5, 2010. http://online.wsj.com/article/SB10001 424052748704631504575531932754922518. html

Christensen, C. (2009). The critical role handwriting plays in the ability to produce high-quality text. In R. Beard, D. Myhill, J. Riley, \& M. Nystrand (Eds.), The Sage handbook of writing development (pp. 284-299). Thousand Oaks, CA: Sage Publications.

Edmonton Public Schools. (2008). Evaluating English Writing. Teacher Resource for Highest Level of Achievement Test, HLAT Writing. 2008 Edition.

Gentry, R. (1982). An analysis of development spelling in GNYS AT WORK. The Reading Teacher, November, 192-200.

Jones, D., \& Christensen, C. (1999). Relationship between automaticity in handwriting and students' ability to generate written text. Journal of Educational Psychology, 91(1), 44-49. 
Joshi, M., Treiman, R., Carreker, S., \& Moats, L (2008). How words cast their spell: Spelling is an integral part of learning the language, not a matter of memorization. American Educator, Winter 2008-2009, 6-8. http:// www.aft.org/pdfs/americaneducator/winter0809/joshi.pdf\#page $=4$

Korbey, H. (2013). Should schools still teach cursive? MindShift: How we will learn. http://blogs.kqed.org/mindshift/2013/06/ should-schools-still-teach-cursive/

Morin, M., LaVoie, N., \& Montesinos, I. (2012). The effects of manuscript, cursive or manuscript/ cursive styles on writing development in Grade 2. Language and Literacy, 14(1), 110-124.

Moss, B. (2004). Teaching expository text structure through information trade book retellings. The Reading Teacher, 57(8), 710-718.

Roessingh, H. (2012a). The Grade 3 Provincial Achievement Tests: In need of revamping? Alberta Journal of Educational Research, 58(3), 425-443.http://ajer.synergiesprairies.ca/ajer/ index.php/ajer/article/view/1057

Roessingh, H. (2012b). The importance of the prompt for eliciting language samples: Insights from research and considerations for practice. TexELT: Texas English Language Teaching, 1(1), 37-56. http://www.textesolv.org
Roessingh, H., \& Douglas, S. (2013). Using lexical profiling tools: Targeting teacher talk and learning tasks to support academic vocabulary development in the mainstream elementary class setting. In M. Cowart \& G. Anderson (Eds.) Teaching and Leading in Diverse Schools. Denton, TX: The Federation of North Texas Universities. In print, August, 2013.

Roessingh, H., \& Elgie, S. (2009). Early language and literacy development among young ELL: Preliminary insights from a longitudinal study. TESL Canada Journal, 26(2), 24-45.

Temple, C., Nathan, R., \& Temple, C. (2013). The beginnings of writing, 4th Edition. New York: Pearson.

Wolf, M. (2007). Proust and the squid: The story and science of the reading brain. New York: Harper.

Wren-Lewis, S. (2011). Review of Effortless attention. Bruya, 2010. Metapsychology: Online reviews. Apr 26th 2011 (Volume 15, Issue 17). http://metapsychology.mentalhelp.net/ poc/view_doc.php?type=book\&id=6051

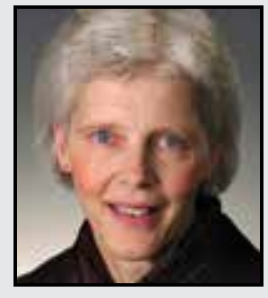

Hetty Roessingh is a professor in the Werklund School of Education, University of Calgary. Her SSHRC-funded program of research involves longitudinal studies of language and literacy development over the educational trajectory K-16. The central role of vocabulary knowledge and its assessment through lexical profiling tools is of particular interest. She works actively with partnering schools to improve early language and literacy outcomes by being engaged in action research projects that focus on high impact classroom practices.

LINK TO:

http://www.lextutor.ca/vp/kids

http://www.readingrockets.org/firstyear/fyt.php?CAT=34 